\title{
Maternal uniparental isodisomy 20 in a foetus with trisomy 20 mosaicism: clinical, cytogenetic and molecular analysis
}

\author{
Voula Velissariou ${ }^{*, 1}$, Thalia Antoniadi ${ }^{2}$, Jolanda Gyftodimou ${ }^{3}$, Katerina Bakou ${ }^{1}$, \\ Maria Grigoriadou ${ }^{3}$, Stavroula Christopoulou ${ }^{1}$, Athina Hatzipouliou ${ }^{1}$, \\ Jackie Donoghue ${ }^{1}$, Panagiotis Karatzis ${ }^{4}$, Efstathia Katsarou ${ }^{5}$ and Michael B Petersen ${ }^{* 3}$
}

${ }^{1}$ Cytogenetics Laboratory, Department of Genetics and Molecular Biology, Mitera Maternity and Surgical Center, Athens, Greece; ${ }^{2}$ Molecular Biology Laboratory, Department of Genetics and Molecular Biology, Mitera Maternity and Surgical Center, Athens, Greece; ${ }^{3}$ Department of Genetics, Institute of Child Health, Athens, Greece; ${ }^{4}$ IVF Unit, Mitera Maternity and Surgical Center, Athens, Greece; ${ }^{5}$ Department of Neurology, 'P. \& A. Kyriakou' Children's Hospital, Athens, Greece

The clinical significance of trisomy $\mathbf{2 0}$ mosaicism detected prenatally remains uncertain due to the rarity of liveborn cases with inconsistent clinical findings, and lack of long-term follow-up and outcome. We describe a case of true trisomy $\mathbf{2 0}$ mosaicism in a liveborn girl with maternal uniparental isodisomy of chromosome $\mathbf{2 0}$ in the diploid blood cells. Trisomy $\mathbf{2 0}$ mosaicism was originally detected in amniotic fluid $(98 \%)$ and was confirmed in the term placenta (100\%), as well as in the blood (10\%) and urine sediment $(100 \%)$ of the neonate. There was intrauterine and postnatal growth retardation, but otherwise the newborn manifested no gross abnormalities. At 9 months of age moderate psychomotor retardation, central hypotonia with peripheral hypertonia, numerous minor morphogenetic variants, marked kyphosis, and extensive Mongolian spot were observed. To our knowledge this represents the first case of trisomy 20 mosaicism detected prenatally and confirmed in different tissues of the newborn, where uniparental disomy was demonstrated in the diploid cell line. The clinical and laboratory findings in our patient are compared with those of five previously reported cases of UPD20, suggesting that maternal UPD20 might be associated with a characteristic phenotype.

European Journal of Human Genetics (2002) 10, 694-698. doi:10.1038/sj.ejhg.5200867

Keywords: trisomy 20 mosaicism; uniparental disomy; prenatal diagnosis; nondisjunction; imprinting

Introduction

Trisomy 20 mosaicism is one of the most common forms of autosomal mosaicism diagnosed prenatally after amniocentesis or chorionic villus sampling (CVS), yet its clinical

*Correspondence: Dr Voula Velissariou; Cytogenetics Laboratory, Department of Genetics and Molecular Biology, Mitera Maternity and Surgical Center, Kifissias Avenue and Erythrou Stavrou 6, GR-151 23 Maroussi, Athens, Greece. Tel: +30 1068 69869; Fax: +30 1068 32 202; E-mail: petersen@otenet.gr and Dr Michael B Petersen, Department of Genetics, Institute of Child Health, 'Aghia Sophia' Children's Hospital, GR11527 Athens, Greece. Tel: +30 107467789 ; Fax: +30 107700111 ; E-mail: inchildh@otenet.gr

Received 17 April 2002; revised 24 June 2002; accepted 28 June 2002 significance remains uncertain. ${ }^{1,2}$ Very few cases have been described previously in which trisomy 20 cells were confirmed in tissues obtained from liveborn infants, and these cases showed no gross anomalies. ${ }^{3-7}$

When trisomy 20 mosaicism is detected during prenatal diagnosis, the rate of an abnormal outcome is $6.5 \%$ with wide variability in phenotype. ${ }^{2}$ Abnormalities in liveborns include growth retardation, hypotonia, structural CNS abnormalities and seizures, facial dysmorphism, failure to thrive, and development delay. The risk of congenital abnormality increases with increasing percentage of the trisomic cell line in amniotic fluid. ${ }^{2}$ Confirmation of trisomy 20 in blood has only been described in one case of a liveborn 
with trisomy 20 in $17 \%$ of foetal cord cells and no dysmorphic features or apparent malformations. ${ }^{6}$

The origin of the extra chromosome 20 has been investigated in one case of an aborted foetus, where generalised trisomy 20 mosaicism was present in different foetal as well as placental tissues, and where the extra chromosome 20 originated from a maternal meiosis II or postzygotic mitotic nondisjunction. ${ }^{8}$ Infants with a normal karyotype from a pregnancy in which a mosaic trisomy cell line was found in amniocytes or trophoblastic cells, are potentially at risk for uniparental disomy (UPD). ${ }^{9}$ There are five reports in the literature of UPD20 (one of which was confined to 20q) and abnormal phenotypic findings (Table 1). ${ }^{10-14}$

Here we describe a baby who was born without gross malformations following prenatal diagnosis of trisomy 20 mosaicism in amniocytes, which was confirmed in urine sediment and blood cells of the newborn, and where maternal uniparental isodisomy for chromosome 20 was detected in the diploid blood cells.

\section{Patient and methods}

\section{Clinical case}

A 36-year-old woman with no previous medical history was referred for cytogenetic prenatal diagnosis due to advanced maternal age and an increased risk in the serum triple test (1:120). Amniocentesis was performed at 21 weeks of gestation. The parents were informed that high level trisomy 20 mosaicism was detected in the amniotic fluid cells and after genetic counselling they elected to continue the pregnancy without further testing. At 36 weeks intrauterine growth retardation (IUGR) and oligohydramnios were reported. At 38 weeks a caesarian section was performed due to IUGR, the birth weight was $1800 \mathrm{~g}$, and no gross abnormalities were observed. During the first days of life the baby was hypertonic especially in the lower limbs and had jittering movements. A mild systolic heart murmur was noted due to a small VSD of membraneous type. Ultrasound of brain, abdomen, and kidneys was normal. Ophthalmologic exam was normal. The baby thrived and was discharged after 4 weeks.

Neurological examination at 9 months of age showed a psychomotor retardation of 2 months. Fundoscopy and acoustic evoked responses were normal. The clinical genetic examination revealed the following findings. The infant sat without support but with marked kyphosis, could not roll over, was alert, followed and grasped objects with a slight ataxia and also had central hypotonia and intermittent peripheral hypertonia. Gap reflex was absent and she had chewing movements which prohibited the inspection of the uvula. Weight was at the 5th, length at the 60th and OFC at the 50th centile. Ear length, palms and middle fingers were at the $75 \mathrm{th}$, and feet at the 50th centile. Thorax circumference was at the 25th and intermamillary distance at the 50th centile.

The following morphogenetic variants were noted: extensive Mongolian spot over the whole dorsal part of the body, dolichocephaly, biparietal narrowing, long, narrow and rounded forehead, protruding lateral occipital bones, small anterior fontanel, long and narrow face, preauricular pits, soft ear cartilages, simple helices and anthelices, posteriorly rotated ears, upward slanting palpebral fissures, heavy epicanthus, blue sclerae, broad and depressed nasal bridge, short and deeply grooved philtrum, cupid's bow of the upper lip, broad upper lip frenulum, thickened gingivae, micrognathia, thin and long neck, small nipples, marked kyphosis, anteriorly placed anus, joint laxity, mild clinodactyly of the 5th fingers, abnormal palmar creases of the left hand, and prominent heels.

\section{Conventional cytogenetic analysis}

Metaphase chromosome preparations were obtained from amniotic fluid cells, peripheral blood lymphocytes, cultured placenta and urine sediment using standard techniques

Table 1 Summary of the clinical, cytogenic and molecular findings in six patients with UPD20

\begin{tabular}{|c|c|c|c|c|c|c|}
\hline $\begin{array}{l}\text { Findings } \\
\text { (reference) }\end{array}$ & $\begin{array}{l}\text { Patient } 1 \\
(10)\end{array}$ & $\begin{array}{l}\text { Patient } 2 \\
(11)\end{array}$ & $\begin{array}{l}\text { Patient } 3 \\
(12)\end{array}$ & $\begin{array}{l}\text { Patient } 4 \\
(13)\end{array}$ & $\begin{array}{l}\text { Patient } 5 \\
(14)\end{array}$ & $\begin{array}{l}\text { Patient } 6 \\
\text { (Present case) }\end{array}$ \\
\hline Maternal age & $?$ & 40 & 39 & 36 & 39 & 36 \\
\hline IUGR & $?$ & + & + & + & - & + \\
\hline Postnatal growth retardation & $?$ & + & + & + & - & $\mathrm{FTT}^{\mathrm{e}}$ \\
\hline Multiple organ malformations & + & - & - & - & - & - \\
\hline Microcephaly & + & + & - & + & - & - \\
\hline Macrocephaly & - & - & + & - & + & - \\
\hline Facial dysmorphism & Severe & Mild & - & Mild & Severe & Mild \\
\hline Strabismus & $?$ & - & + & + & - & - \\
\hline Psychomotor retardation & $?$ & - & - & + & + & + \\
\hline Hyperactivity & $?$ & + & - & - & - & Not relevant \\
\hline Karyotype & $\begin{array}{l}\text { Translocation/ } \\
\text { Trisomy }^{\mathrm{a}}\end{array}$ & $\begin{array}{l}\text { Normal/ } \\
\text { Marker }^{b}\end{array}$ & Normal & Normal $^{c}$ & Normal & $\begin{array}{l}\text { Normal/ } \\
\text { Trisomy }\end{array}$ \\
\hline UPD studies & $\begin{array}{l}\text { Paternal } \\
\text { isodisomy }\end{array}$ & $\begin{array}{l}\text { Maternal iso/ } \\
\text { heterodisomy }\end{array}$ & $\begin{array}{l}\text { Maternal } \\
\text { heterodisomy }\end{array}$ & $\begin{array}{l}\text { Maternal iso/ } \\
\text { heterodisomy }\end{array}$ & $\begin{array}{l}\text { Paternal } \\
\text { isodisomy }\end{array}$ & $\begin{array}{l}\text { Maternal } \\
\text { isodisomy }\end{array}$ \\
\hline
\end{tabular}

${ }^{a} \operatorname{mos} 45, X Y,-20,-20,+$ ter rea(20;20)(p13;p13)/46,XY,-20,+ter rea(20;20)(p13;p13). ${ }^{b}$ mos 47,XY,+mar(20)/46,XY. ${ }^{c} m o s ~ 47, X X,+20 / 46, X X$ in amniotic fluid. ${ }^{d}$ UPD $20 \mathrm{q}$ whereas $20 \mathrm{p}$ markers showed biparental inheritance. ${ }^{\mathrm{e}} \mathrm{FTT}=$ failure to thrive. 
(Table 2). Conventional cytogenetic analyses were carried out using GTG banding. In all tissues 100 cells from two different primary cultures were analysed for chromosome number, and five amniotic cells were karyotyped and captured by computer imaging (Cytovision system, Image Analysis, Applied Imaging, Sunderland, UK).

\section{FISH analysis}

FISH analysis in peripheral blood lymphocytes of the newborn was performed according to the manufacturer's instructions using a centromeric probe for chromosome 20 (Cytocell Limited, Oxfordshire, UK). Scoring was performed on interphase nuclei in $24 \mathrm{~h}$ blood lymphocyte cultures.

\section{Molecular analysis}

Genomic DNA was extracted from EDTA-anticoagulated blood with the use of QIAamp DNA Blood Mini Kit (QIAGEN), and from the term placenta with the use of QIAamp DNA Mini Kit (QIAGEN). Twelve microsatellite DNA polymorphisms due to either dinucleotide or tetranucleotide repeats from human chromosome 20 were detected by PCR amplification of genomic DNA (Table 3). Information on the markers used can be found elsewhere. ${ }^{15-19}$ The order of the markers, which span the short and long arms of human chromosome 20, was known from linkage analysis $^{20}$ or from the sequence map of human chromosome 20 (NCBI, http://www.ncbi.nlm.nih.gov). PCR amplification, end-labelling of primer with ${ }^{32} \mathrm{P}$, PAGE of the amplification products, and autoradiography were performed according to previously published protocols. ${ }^{15,21}$ The parental origin of the additional chromosome 20 in the trisomic placenta was studied by scoring the polymorphic alleles and by dosage analysis (ratio between the intensity of two allelic fragments by visual inspection of the autoradiogram). The visual scoring was done by two independent observers. The validity of this PCR method for dosage analysis has previously been demonstrated by densitometry, $^{22}$ and in the case of mosaicism the extra chromosome can be detected by dosage analysis when the trisomic cell line is present in at least $20 \%$ of the cells analysed. ${ }^{23}$ Markers heterozygous in the parent contributing the extra chromosome were identified and scored in the proband as reduced or non-reduced to homozygosity. ${ }^{24}$

Table 2 Results of cytogenetic analysis

\begin{tabular}{lll}
\hline Cells & $\begin{array}{l}\text { Number of cells with } \\
\text { trisomy 20 }\end{array}$ & $\begin{array}{l}\text { Chromosome } \\
\text { constitution }\end{array}$ \\
\hline Amniotic fluid & $47, \mathrm{XX},+20[98] / 46, \mathrm{XX}[2]$ & $\begin{array}{l}\text { High level mosaicism } \\
\text { Trisomy } 20\end{array}$ \\
Placenta & $47, \mathrm{XX},+20[100]$ & Trisomy 20 \\
Urine sediment & $47, \mathrm{XX},+20[100]$ & Normal \\
Blood (72 h) & $46, \mathrm{XX}[100]$ & Low level mosaicism \\
Blood (24 h) [FISH] $47, \mathrm{XX},+20[10] / 46, \mathrm{XX}[90]$ &
\end{tabular}

\section{Results}

The results of the cytogenetic analysis are presented in Table 2. In the amniotic fluid 98/100 (98\%) cells were found to have trisomy $20(\operatorname{mos} 47, \mathrm{XX},+20 / 46, \mathrm{XX})$. In the placenta and urine sediment all cells were trisomic for chromosome 20. In the peripheral blood in the $72 \mathrm{~h}$ culture all cells were found to have a normal karyotype, whereas in the $24 \mathrm{~h}$ culture 10/100 (10\%) interphase cells showed three signals for chromosome 20 with the FISH analysis.

The results of the molecular analysis are presented in Table 3. No third allele was detected by any marker studied in the placenta representing the trisomic cell line. By dosage analysis the origin of the extra chromosome 20 was maternal by several markers (Table 3). All informative markers showed reduction to homozygosity in the placenta, consistent with a mitotic (postzygotic) origin of nondisjunction. With polymorphic markers D20S115, D20S87, D20S45, D20S89, and D20S75 maternal uniparental isodisomy was demonstrated in the blood. When using marker D20S75 a faint paternal allele was observed indicating the presence of a trisomic cell line at a low percentage.

\section{Discussion}

Trisomy 20 mosaicism remains a serious dilemma in prenatal diagnosis and genetic counselling. There are many unresolved questions regarding its origin, specific somatic tissue involvement, clinical implications, and possible long-term outcome.

When trisomy 20 mosaicism is detected during prenatal diagnosis there is an overall $6.5 \%$ risk of an abnormal

Table 3 Results of molecular analysis

\begin{tabular}{|c|c|c|c|c|}
\hline Locus $^{a}$ & Mo & $\mathrm{Fa}$ & Placenta & Blood \\
\hline D20S117 & $a b$ & aa & aaa $\mathrm{R}$ & aа \\
\hline D20S82 & $\mathrm{ac}$ & $a b$ & aaa $\mathrm{R}$ & aa \\
\hline D20S115 & CC & $a b$ & bcc M & cc mUPD \\
\hline D20S66 & $a b$ & & aaa $\mathrm{R}$ & аa \\
\hline D20S81 & aа & $a b$ & aаa & aа \\
\hline D20S87 & $a b$ & $\mathrm{~cd}$ & bbd MR & bb mUPD \\
\hline D20S45 & $\mathrm{ac}$ & $a b$ & bcc MR & cc mUPD \\
\hline D20S85 & aa & $a b$ & $a a b$ & aa \\
\hline ADA & bc & $a b$ & bbb R & $\mathrm{bb}$ \\
\hline D20S89 & $\mathrm{ac}$ & $a b$ & bcc MR & cc mUPD \\
\hline D20S75 & bc & $\mathrm{ad}$ & bbd MR & $\mathrm{bb}(\mathrm{d})^{\mathrm{b}}$ mUPD \\
\hline D20S25 & bc & $a b$ & bbb R & $\mathrm{bb}$ \\
\hline
\end{tabular}

${ }^{a}$ The loci on chromosome 20 are ordered in a column corresponding to their relative chromosomal order based on linkage analysis or the sequence map of human chromosome 20. The three parts of the data correspond to mother (Mo), father $(\mathrm{Fa})$, and proband (Placenta=newborn placenta, Blood=newborn blood), respectively. The characters in the genotypes represent the different alleles at a specific locus. $M=$ maternal origin of the extra chromosome 20 as determined by the respective DNA marker. $\mathrm{R}=$ reduction to homozygosity for a given DNA marker. $\mathrm{mUPD}=$ maternal uniparental disomy as determined by the respective DNA marker. ${ }^{\mathrm{b}} \mathrm{A}$ faint allele $d$ was observed indicating the presence of a trisomic cell line in low percentage. 
outcome with no consistent pattern of abnormalities. ${ }^{2}$ It is estimated that in a case with $98 \%$ trisomy mosaicism like ours, there is an approximately $20 \%$ risk for congenital abnormalities. ${ }^{2}$ Confirmation of trisomy 20 seems rare in the blood. However, it is recommended to perform FISH analysis to limit possible misdetection of the trisomy in cell cultures due to selection against the aberrant line. In one liveborn case, trisomy 20 mosaicism was demonstrated in $54 \%$ of skin fibroblast interphases by FISH analysis, whereas all blood metaphases were normal. ${ }^{7}$ In our case we demonstrated with FISH and molecular analysis that a trisomic cell line existed in the blood in low percentage. This, together with the finding of trisomy 20 in the urine sediment, confirmed that in our case the cytogenetic aberration was truly present in various tissues of the baby. In the previously reported case, although the baby showed only minor phenotypic signs (bilateral epicanthal folds and delayed closure of fontanel), there was a considerable developmental delay in gross and fine motor skills at the age of 15 months. $^{7}$ In our case, moderate psychomotor retardation, central hypotonia with peripheral hypertonia, numerous minor morphogenetic variants, marked kyphosis, and extensive Mongolian spot were noted at 9 months of age.

The parental origin of the extra chromosome in trisomy 20 mosaicism has only been studied in one previous case of an aborted foetus with trisomy 20 mosaicism verified in a variety of foetal tissues, where the origin was shown to be maternal. ${ }^{8}$ In that case, 10 dinucleotide repeat polymorphisms spaced along the short and long arms of chromosome 20 failed to reveal three different alleles in the proband DNA, and as no recombination was observed between markers, the findings suggested that the nondisjunction event most likely occurred postzygotically. ${ }^{8}$ Biparental inheritance was detected in the diploid chorionic villi. ${ }^{8}$ The fact that $78 \%$ of the reported prenatal cases of trisomy 20 mosaicism were diagnosed after an amniocentesis because of advanced maternal age, however, suggests a maternal age effect (and maternal meiotic origin in the majority of cases) as seen in other trisomies, ie 13, 16, 18, 21 , and $X^{2,25}$ A molecular study of seven spontaneous abortions with nonmosaic trisomy 20 showed meiotic origin in five cases (three maternal and two undetermined) and probable somatic origin in two cases. ${ }^{26}$

Uniparental disomy 20 has been demonstrated in five previous cases (Table 1). An imprinted gene (GNAS1) has been reported in 20q13.3, inactivating mutations of which cause pseudohypoparathyroidism, Albright hereditary osteodystrophy or progressive osseous heteroplasia. ${ }^{14,27}$ In all four cases with complete UPD20 there were abnormal phenotypic findings, with IUGR and/or postnatal growth retardation being the dominant features (Table 1). A preliminary report described paternal isodisomy in a patient with severe phenotypic abnormalities, including congenital malformations involving multiple organ systems, microce- phaly, and facial dysmorphism (patient 1). ${ }^{10}$ However, the patient had a complex mosaic karyotype consisting of a $45, \mathrm{XY},-20,-20,+$ ter rea $(20 ; 20)(\mathrm{p} 13 ; \mathrm{p} 13)$ cell line and a trisomic cell line ( $8 \%$ in skin), a fact which makes it difficult to assess the contribution of UPD to the phenotype. Patient 2 also had a complex karyotype with a tiny supernumerary marker chromosome $20 \quad(44 \%$ of blood lymphocytes), which was comprised of centromeric and heterochromatic material and would presumably have had little effect on the phenotype. ${ }^{11}$ DNA microsatellite analysis was consistent with a maternal meiosis II error. ${ }^{11}$ In patient 3 with a normal karyotype in peripheral lymphocytes, DNA analysis showed heterodisomy of all informative markers consistent with a maternal meiosis I nondisjunction. ${ }^{12}$ In patient 4 with normal karyotype in blood and trisomy 20 mosaicism in amniotic fluid, the DNA microsatellite analysis showed alternating regions of iso- and heterodisomy consistent with a maternal meiotic origin. ${ }^{13}$ In patient 5 the paternal isodisomy was confined to chromosome 20q, whereas markers from 20p showed normal Mendelian inheritance. ${ }^{14}$ The patient showed lack of the maternal methylation pattern at the GNAS1 gene located in 20q13.3 and the patient was diagnosed with pseudohypoparathyroidism due to parathyroid hormone (PTH) resistance. The GNAS1 gene encodes the alpha subunit of the stimulatory G protein (Gsalpha), which is the mediator of the effect of PTH. The patient had craniosynostosis and developmental delay during infancy. ${ }^{14}$ The clinical findings in patients 2,3 and 4 including our patient (Table 1), where maternal UPD20 has been demonstrated, are quite similar, with the dominant feature being growth failure pre- and/or postnatally. This suggests that maternal UPD20 could be associated with a characteristic phenotype, although it cannot be ruled out that undetected trisomy 20 in other tissues than those tested could contribute to the phenotype. For example, in patients 3 and 4 (Table 1) no tissues other than blood were tested, and the authors commented that even if there is trisomy 20 mosaicism in the genito-urinary or cardiac tissues, it is unlikely to account for the abnormal clinical findings. ${ }^{13}$ We suggest, that in order to evaluate the true clinical significance of UPD20, it is advisable to test more than one tissue of the patient and to perform interphase FISH studies. It could be speculated that the variability in the phenotype of trisomy 20 mosaicism may be attributed primarily to the distribution of the trisomic cell line in the various tissues, and also to the presence of uniparental disomy in the diploid cell line (imprinting) and finally to the presence of homozygosity for recessive genes in case of isodisomy. The precise characterisation of a UPD20 syndrome will depend on identification of more patients including detailed clinical description and follow-up, and additional insight into imprinting of genes on chromosome 20 will be important to understanding the underlying genetic mechanisms. 


\section{Acknowledgements}

This work was supported by a COPERNICUS-2 grant from the European Commission (ICA2-CT-2000-10012).

\section{References}

1 Hsu LYF, Kaffe S, Perlis TE: A revisit of trisomy 20 mosaicism in prenatal diagnosis - an overview of 103 cases. Prenat Diagn 1991; 11: 7-15.

2 Wallerstein R, Yu M-T, Neu RL et al: Common trisomy mosaicism diagnosed in amniocytes involving chromosomes 13, 18, 20 and 21: karyotype-phenotype correlations. Prenat Diagn 2000; 20: $103-122$.

3 Miny P, Karabacak Z, Hammer P, Schulte-Vallentin M, Holzgreve $\mathrm{W}$ : Chromosome analyses from urinary sediment: postnatal confirmation of a prenatally diagnosed trisomy 20 mosaicism. N Engl J Med 1989; 320: 809.

4 Park JP, Moeschler JB, Rawnsley E, Berg SZ, Wurster-Hill DH: Trisomy 20 mosaicism confirmed in a phenotypically normal liveborn. Prenat Diagn 1989; 9: 501-504.

5 Van Dyke DL, Roberson JR, Babu VR, Weiss L, Tyrkus M: Trisomy 20 mosaicism identified prenatally and confirmed in foreskin fibroblasts. Prenat Diagn 1989; 9: 601-602.

6 Brothman AR, Rehberg K, Storto PD, Phillips SE, Mosby RT: Confirmation of true mosaic trisomy 20 in a phenotypically normal liveborn male. Clin Genet 1992; 42: 47-49.

7 Reish O, Wolach B, Amiel A, Kedar I, Dolfin T, Fejgin M: Dilemma of trisomy 20 mosaicism detected prenatally: is it an innocent finding? Am J Med Genet 1998; 77: 72- 75.

8 Micale MA, Wolff DJ, Dickerman LH, Redline R, Conroy JM, Schwartz S: Cytogenetic and molecular genetic characterization of trisomy 20 mosaicism in fetal blood and tissues. Prenat Diagn 1996; 16: $893-897$.

9 Kotzot D: Abnormal phenotypes in uniparental disomy (UPD): fundamental aspects and a critical review with bibliography of UPD other than 15. Am J Med Genet 1999; 82: 265-274.

10 Spinner NB, Rand E, Bucan M et al: Paternal uniparental isodisomy for human chromosome 20 and absence of external ears. Am J Hum Genet 1994; 55 (Suppl): A118.

11 Chudoba I, Franke Y, Senger G et al: Maternal UPD 20 in a hyperactive child with severe growth retardation. Eur J Hum Genet 1999; 7: 533 - 540 .

12 Eggermann T, Mergenthaler S, Eggermann K et al: Identification of interstitial maternal uniparental disomy (UPD) (14) and complete maternal UPD(20) in a cohort of growth retarded patients. J Med Genet 2001; 38: 86-89.

13 Salafsky IS, MacGregor SN, Claussen U, von Eggeling F: Maternal UPD 20 in an infant from a pregnancy with mosaic trisomy 20. Prenat Diagn 2001; 21: 860-863.
14 Bastepe M, Lane AH, Juppner H: Paternal uniparental isodisomy of chromosome 20q - and the resulting changes in GNAS1 methylation - as a plausible cause of pseudohypoparathyroidism. Am J Hum Genet 2001; 68: $1283-1289$.

15 Economou EP, Bergen AW, Warren AC, Antonarakis SE: The polydeoxyadenylate tract of Alu repetitive elements is polymorphic in the human genome. Proc Natl Acad Sci USA 1990; 87: 2951 - 2954.

16 Hazan J, Dubay C, Pankowiak M-P, Becuwe N, Weissenbach J: A genetic linkage map of human chromosome 20 composed entirely of microsatellite markers. Genomics 1992; 12: 183-189.

17 NIH/CEPH Collaborative Mapping Group: A comprehensive genetic linkage map of the human genome. Science 1992; 258 $67-86$.

18 Melis R, Bradley P, Elsner T et al: Polymorphic SSR (SimpleSequence-Repeat) markers for chromosome 20. Genomics 1993; 16: $56-62$.

19 Dib C, Faure S, Fizames C et al: A comprehensive genetic map of the human genome based on 5,264 microsatellites. Nature 1996; 380: $152-154$.

20 Matise TC, Perlin M, Chakravarti A: Automated construction of genetic linkage maps using an expert system (MultiMap): a human genome linkage map. Nat Genet 1994; 6: 384-390.

21 Petersen MB, Economou EP, Slaugenhaupt SA, Chakravarti A, Antonarakis SE: Linkage analysis of the human HMG14 gene on chromosome 21 using a GT dinucleotide repeat as polymorphic marker. Genomics 1990; 7: 136-138.

22 Petersen MB, Schinzel AA, Binkert F et al: Use of short sequence repeat DNA polymorphisms after PCR amplification to detect the parental origin of the additional chromosome 21 in Down syndrome. Am J Hum Genet 1991; 48: 65 - 71.

23 Karadima G, Bugge M, Nicolaidis P et al: Origin of nondisjunction in trisomy 8 and trisomy 8 mosaicism. Eur J Hum Genet 1998; 6 : $432-438$.

24 Chakravarti A, Slaugenhaupt SA: Methods for studying recombination on chromosomes that undergo nondisjunction. Genomics 1987; 1: 35-42.

25 Robinson WP, Binkert F, Bernasconi F, Lorda-Sanchez I, Werder EA, Schinzel AA: Molecular studies of chromosomal mosaicism: relative frequency of chromosome gain or loss and possible role of cell selection. Am J Hum Genet 1995; 56: 444-451.

26 Robinson WP, Bernasconi F, Lau A, McFadden DE: Frequency of meiotic trisomy depends on involved chromosome and mode of ascertainment. Am J Med Genet 1999; 84: 34-42.

27 Shore EM, Ahn J, Jan de Beur S et al: Paternally inherited inactivating mutations of the GNAS1 gene in progressive osseous heteroplasia. N Engl J Med 2002; 346: 99-106. 